\title{
FEATURES OF SOUND CLASSIFICATION SCHEME DESIGNATED TO LABEL BUILDINGS IN LITHUANIA
}

\author{
Aleksandras JAGNIATINSKIS ${ }^{\mathrm{a}}$, Boris FIKS ${ }^{\mathrm{a}}$, Marius MICKAITIS ${ }^{\mathrm{b}}$, Ritoldas ŠUKYS ${ }^{\mathrm{c}}$ \\ ${ }^{a}$ Laboratory of Acoustics, Scientific Institute of Thermal Insulation, Vilnius Gediminas Technical University, \\ Linkmenu str. 28, 08217, Vilnius, Lithuania \\ ${ }^{b}$ Department of Architectural Engineering, Faculty of Civil Engineering, Vilnius Gediminas Technical University, \\ Sauletekio ave. 11, 10223, Vilnius, Lithuania \\ ${ }^{c}$ Department of Labour Safety and Fire Protection, Faculty of Civil Engineering, \\ Vilnius Gediminas Technical University, Sauletekio ave. 11, 10223, Vilnius, Lithuania
}

Received 08 Jan 2016; accepted 07 Nov 2016

\begin{abstract}
In Lithuania's case, the legal requirements for the building acoustic quality since the year 2004 has been expressed through the sound classification scheme (SCS). The relationship of the subjective indoor acoustic comfort with the value of objective sound insulation was considered as a core for the classification scheme. SCS was designed to provide at least one sound class as a request for the newly erected building, other lower classes for reconstructed buildings and higher classes for premises with enhanced acoustic comfort. The adopted scheme contains five sound classes with various steps between them and is based on rating by two different sound insulation descriptors both having the same limit value. A request to protect against noise for newly erected and reconstructed buildings was enforced via the mandatory pre-completion acoustical testing. The database collected during testing allowed for the analysis of about 2000 in situ measurements of sound insulation properties of building partitions. It showed that the possibility of selecting either of the two airborne sound insulation descriptors $D_{\mathrm{n}, T, \mathrm{w}}$ or $R^{\prime}{ }_{\mathrm{w}}$ ensures better conformity with subjective comfort perception. This paper also addresses the particularities and advantages of simultaneous application of two different descriptors for regulation of sound insulation performance of dwellings.
\end{abstract}

Keywords: building acoustics, acoustic comfort, sound insulation, sound class, pre-completion tests.

\section{Introduction}

As one of the negative impacts of the technological progress in today's society, our environment is threatened by an increasing number of indoor and outdoor noise sources. An increase in various functions in the city leads to concentration of various noise sources from living, working, entertaining activities and transportation. The aim of designing and constructing smart and sustainable buildings affects the building methods and quality assessment. Different technical installations are used in the modern buildings to improve the comfort of the inhabitants, such as heating, air-conditioning, energy conservation and other systems. Thus, more potential noise sources are being incorporated in buildings than ever before. On the other hand, more lightweight and pre-fabricated elements are used. Taken together, these trends threaten the acoustic comfort of newly built buildings. More equipment are mounted in dwellings made of lighter building elements, eliciting more structure-borne sound.

It is a well-established fact that proper acoustic comfort represents a necessary condition for human health, since people who are exposed to noise in their homes and working places are more susceptible to stress-related disorder than people living and working in quiet surroundings. Fortunately, the increasingly noisy environment has triggered our society's awareness of the necessity to maintain an appropriate level of sound insulation in buildings. This consciousness was translated into internationally accepted standards, maintaining the acoustic comfort of people's working and living environment. Architects and engineers are challenged to design and construct quieter buildings that meet the growth in consumer demand. Nowadays, a higher acoustic quality is required and should be realized.

Different needs for quietness in working and living environment can be expressed by the classification of acoustics performance as a set of at least two classes with different limit values for sound quality. The first attempt to introduce a classification scheme in 1993 was the French qualification system (La méthode qualitel 2008; Guigou-Carter et al. 2012). Germany, in 1994, developed

Corresponding Marius Mickaitis

E-mail:marius.mickaitis@vgtu.lt 
a draft of the first version of the VDI standard, which comprises three sound classes (VDI 4100:2012). Some years later, the Nordic countries initialized a project to look at standardizing the sound classification scheme (SCS) for dwellings (INSTA 122:1998). As a result, four sound classes were considered for setting in Sweden (SS 25267:2004), Norway (NS 8175:2012), Denmark (DS 490:2007), Iceland (IST 45:2011) and Finland (SFS 5907:2004). SCSs were adopted as national standards with some modifications of the descriptors used and applicability for buildings of various purpose. Today's definition of a SCS requires a minimum set of three sound classes with different sound insulation performance levels (Rasmussen, Machimbarrena 2014b).

A national SCS was developed in Lithuania to identify the best approach to implement the essential requirement "protection against noise", which was first defined in the Construction Product Directive and has since been moved to Regulation No 305/2011 for construction works (Regulation 2011). The classification of acoustic conditions in buildings was put into force as a building technical regulation (STR 2.01.07:2003) in 2004 by an order issued by the minister of the environment (STR 2003). Limit values presented in the $\mathrm{C}$ and $\mathrm{E}$ sound classes were linked to the building code (BC). These values were based on analysis of the progress in sound insulation requirements for dwellings in EU countries as well as on results of additional investigations in local dwellings. The obtained mean sound insulation value corresponds to the typical performance of the existing residential buildings (Jagniatinskis 2003).

National SCS comprises five sound classes similar to those suggested in the Netherlands (NEN 1070:1999) and Austrian standards (ÖNORM B 8115-5:2012). Limit values of main class $C$ were designated for new buildings, while the lowest class E criteria were applicable for the existing buildings after renovations took place. In case of the need for better acoustical comfort conditions, voluntary applicable limit values are presented in the enhanced A, B (new buildings) as well as D sound classes (old buildings). This document is applicable to the buildings of various purposes and is mainly concerned with dwellings, apartment buildings and existing housing stock.

Many efforts are made nowadays for the harmonization of various available schemes in European countries for the classification of acoustic quality of the indoor environment in buildings. In 2009, the COST Action TU0901 was established, and after 4 years of activities a proposal was prepared (Rasmussen, Machimbarrena 2014b). The investigations carried out in the COST Action TU0901 (2016) concerned proposals for an acoustic classification scheme for dwellings only. The scheme was developed using the COST compounds' 6 (six) sound classes (from A [highest] to $\mathrm{F}$ [lowest]), with $4 \mathrm{~dB}$ steps between classes and an additional "NPD" ("no performance determined") option. This scheme in global approach is the first step towards harmonization of the legal regulation of sound insulation because the situation may be modified in the context of sustainability assessment for buildings as an analogy to energy labelling systems.

During the last 15 years, the progress in developing SCS for buildings has been described in various works (Nurzynski 2007; Gerretsen 2009; Rasmussen, Rindel 2003, 2010; Rasmussen 2004, 2010, 2011, 2014; Jagniatinskis et al. 2013; Rasmussen, Machimbarrena 2014a, 2014b; Berardi, Rasmussen 2015). The national systems for acoustic classification in buildings were prepared separately at different times, and are specific for different countries. An overview of the 10 existing SCSs for dwellings (NEN 1070:1999; STR 2.01.07:2003; SFS 5907:2004; SS 25267:2004; DS 490:2007; IST 45:2011; NS 8175:2012; UNI 11367:2010; VDI 4100:2012; ÖNORM B 8115-5:2012) was reported in a few publications (Jagniatinskis et al. 2013; Rasmussen, Machimbarrena 2014a; Rasmussen, Rindel 2003, 2010; Jagniatinskis, Fiks 2004, 2009) and is presented in a modified form in Table 1.

Table 1. Implementation of sound classification schemes' in European countries (modified from Rasmussen, Machimbarena 2014b; Rasmussen 2014. Data from July 2014)

\begin{tabular}{|c|c|c|c|c|c|}
\hline Country & Sound classes & $\begin{array}{l}\text { SCS Reference } \\
\text { (latest version) }\end{array}$ & $\begin{array}{l}\text { Classes for new } \\
\text { dwellings }\end{array}$ & $\begin{array}{c}\text { Classes for "old" } \\
\text { dwellings }\end{array}$ & $\begin{array}{l}\text { BC link to } \\
\text { SCS }\end{array}$ \\
\hline Austria (AT) & $\mathrm{A} / \mathrm{B} / \mathrm{C} / \mathrm{D} / \mathrm{E}$ & ÖNORM B 8115-5:2012 & $\mathrm{A}, \mathrm{B}, \mathrm{C}$ & $\mathrm{D}, \mathrm{E}$ & No \\
\hline Denmark (DK) & $\mathrm{A} / \mathrm{B} / \mathrm{C} / \mathrm{D}$ & DS 490:2007 & $\mathrm{A}, \mathrm{B}, \mathrm{C}$ & $\mathrm{D}$ & Yes \\
\hline Finland (FI) & $\mathrm{A} / \mathrm{B} / \mathrm{C} / \mathrm{D}$ & SFS 5907:2004 & $\mathrm{A}, \mathrm{B}, \mathrm{C}$ & $\mathrm{D}$ & No \\
\hline Germany (DE) & $\mathrm{III} / \mathrm{II} / \mathrm{I}$ & VDI 4100:2012 & III, II, I & None & No \\
\hline Iceland (IS) & $\mathrm{A} / \mathrm{B} / \mathrm{C} / \mathrm{D}$ & IST $45: 2011$ & $\mathrm{~A}, \mathrm{~B}, \mathrm{C}$ & $\mathrm{D}$ & Yes \\
\hline Italy (IT) & I/II/III/IV & UNI 11367:2010 & I/II/III/IV & None & No \\
\hline Lithuania (LT) & $\mathrm{A} / \mathrm{B} / \mathrm{C} / \mathrm{D} / \mathrm{E}$ & STR 2.01.07:2003 & $\mathrm{A}, \mathrm{B}, \mathrm{C}$ & $\mathrm{D}, \mathrm{E}$ & Yes \\
\hline Netherlands (NL) & I/II/III/IV/V & NEN 1070:1999 & I/II/III & $\mathrm{IV}, \mathrm{V}$ & No \\
\hline Norway (NO) & $\mathrm{A} / \mathrm{B} / \mathrm{C} / \mathrm{D}$ & NS 8175:2012 & $\mathrm{A}, \mathrm{B}, \mathrm{C}$ & $\mathrm{D}$ & Yes \\
\hline Sweden (SE) & $\mathrm{A} / \mathrm{B} / \mathrm{C} / \mathrm{D}$ & SS $25267: 2004$ & $\mathrm{~A}, \mathrm{~B}, \mathrm{C}$ & $\mathrm{D}$ & Yes \\
\hline
\end{tabular}


The different classes given in the classification schemes are intended to reflect the different needs for acoustical comfort levels. Taking into account economic factors, different classes in the same scheme were given different descriptors, as in the Lithuanian case. Considering these classification schemes, variations can be found in the following (cf. Rasmussen, Machimbarrena 2014b):

- Descriptors for sound insulation and noise criteria;

- Number of quality classes and steps between the classes;

- Applicability of the spectrum adaptation term according to ISO 717 series looking to extend frequency range under consideration;

- Sound insulation performance values internally in dwellings;

- Common or separate quality levels for multi-storey and row housing;

- Balance between criteria for airborne and impact sound insulation;

- Relation to legal requirements for buildings.

Note that the status of the classification schemes in relation to the legal requirements varies. In five Nordic countries, the Netherlands, Germany, Austria and Italy, the developed SCS was issued as national standards. The schemes were linked to the BC (regulatory requirements) in most of the Nordic countries. Only in Lithuania was the SCS issued as a national building technical regulation. In some countries, the classification label is voluntary and there is no link between the $\mathrm{BC}$ and the classification standard. In other countries, these are strongly "integrated" in the BC, which refers to a specific class in the classification standard rather than just describing the performance of requirements.

SCSs implemented in Nordic countries are based on a common Nordic standard draft (INSTA 122:1998), following several investigations. However, the national schemes were published at different times and are, unfortunately, not identical. In Denmark, Finland, Iceland, Norway, Sweden and Lithuania, class C corresponds to the limit values as the legal requirements for new buildings, and the classes A and B are designated to voluntary applications looking for values that define higher levels of acoustic comfort. Referring to a class, the $\mathrm{BC}$ draws attention to the fact that the legal requirements are minimum acceptable requirements. But possibilities for voluntarily selected specification for better acoustic quality remain. If a classification scheme is not linked to building regulations, its impact will probably be less strong, unless there are other incentives.

As an alternative or a supplement to extensive classification schemes, some countries have defined a simple set of criteria for increased acoustical comfort: for example, an annex added to the document describing the legal requirements, thus reducing the need for a classification scheme. Such criteria were set in, for example, Austria and Germany. Increased comfort criteria are also inherent in the Swiss regulations and in the new Belgian acoustic requirements.

Among the various available sound insulation descriptors presented in papers (Jagniatinskis et al. 2013; Rasmussen, Machimbarrena 2014b; Rasmussen, Rindel 2003, 2010; Jagniatinskis, Fiks 2004, 2009), EU countries mainly use $D_{\mathrm{n} T, \mathrm{w}}$ or $R_{\mathrm{w}}$ for airborne sound and $L^{\prime}{ }_{\mathrm{n} T, \mathrm{w}}$ or $L_{\mathrm{n}, \mathrm{w}}$ for impact sound. Note that these descriptors were defined for the $100-3150 \mathrm{~Hz}$ frequency range and are sometimes additionally adjusted with the spectra adaptation term. Particularities of these descriptors were widely investigated especially with regard to application for airborne and impact sound insulation between dwellings as well as the usage of spectra adaptation terms (Rasmussen, Rindel 2003, 2010; Rasmussen 2004; Jagniatinskis, Fiks 2004; Scholl et al. 2011; Garg et al. 2013; Ljunggren et al. 2014). The legal values for new buildings in European countries vary from approximately $50-55 \mathrm{~dB}$ for airborne sound insulation and from approximately $62-48 \mathrm{~dB}$ for impact sound insulation (Rasmussen, Machimbarrena 2014b; Rasmussen 2010; Rasmussen, Rindel 2010; Jagniatinskis, Fiks 2004). Harmonization of these values is not possible due to the differences in buildings traditions, materials used and climatic conditions in different European regions or countries (Rasmussen, Machimbarrena 2014a). However, other features of the requirements and their adaptation in SCS may be regularized.

\section{SCSs' configuration}

Some common advantages of developed SCS, as well as the experience received during pilot implementation of SCS in national building regulation together with the large number of in situ measurements accomplished during acoustic testing in buildings, allow for the need to consider the following provisions.

\subsection{Types of building to be taken into consideration}

Types of building (premises, protected against noise areas in building, etc.) that are mainly considered in developed SCS: habitable premises (multi-storey dwellings and row housing); temporary residences (hotels, hostels, etc.) and non-residential premises. Type of non-residential premises based on purpose: educational (classrooms in schools, auditoria, etc.); medical (hospitals, polyclinics, ambulatories); offices, industrial areas and large halls (conference rooms, airports, etc.). The case of a combined type of residential and non-residential premises may also be taken into consideration.

\subsection{Acoustical criteria of building elements into consideration}

A list of acoustical properties of building elements and building areas must be created. These elements (called as acoustic elements) are characterized by different 
descriptors, which are defined in the relevant standards (ISO 16283-1:2014; ISO 16283-2:2015; ISO 16283-3:2016) for:

1. Airborne sound insulation between horizontally adjacent rooms (vertical partition - wall);

2. Airborne sound insulation between vertically adjacent rooms (horizontal partition - floor);

3. Impact sound insulation between vertically adjacent rooms (horizontal partition - floor);

4. Airborne sound insulation between room and corridor or staircase (door);

5. Sound insulation from outdoor noise for whole façade (façade partition wall with window);

6. Reverberation time in enclosed premises and areas sensitive to indoor noise (classrooms, conference halls, corridors, etc.).

This list may also incorporate a variety of constructions in the building, for example, a floor between habitable rooms and a floor between habitable rooms and a common garage. Service equipment like lifts, mechanical ventilation, mechanical car park door, heating and cooling installations, toilets, etc. that generate airborne and structure-borne (vibration) noise may also be incorporated. The peculiarities of application of various descriptors for in situ measurements, especially for airborne and impact sound insulation as well as the façade sound insulation, are examined in the next sections. The items of this list present a core of SCS in the form of separate tables where the demands for respective acoustic property are specified.

\subsection{List of descriptors for definition of acoustical properties}

Descriptors available in relevant standards (ISO 162831:2014; ISO 16283-2:2015; ISO 16283-3:2016) are applicable to express the stated acoustical properties of building elements (rating descriptors). The peculiarities of application of various descriptors for in situ measurements, especially for airborne and impact sound insulation as well as for façade sound insulation, must be examined.

\subsection{Number of acoustic classes}

The list of acoustic classes must incorporate the following:

- Main basic acoustic class for newly erected buildings that can be accepted as legal requirement for new dwellings (class $\mathrm{C}$ in Lithuanian case);

- Acoustic class for the existing buildings that can be accepted as a legal requirement for renovated housing stock without changing the usage (class $\mathrm{E}$ in Lithuanian case);

- At least two acoustic classes with enhanced acoustical properties for newly erected as well as renovated buildings (classes B and D in Lithuanian case);

- At least one class with highest acoustical comfort corresponding to technical progress (class A in Lithuanian case).
From this explanation, the need to have at least five classes was justified in developing an SCS to specify a range of acoustic comfort levels in buildings. Lithuanian SCS contains five classes with an additional option "NPD" for performance that does not comply with class $\mathrm{E}$ at least.

\subsection{Limit values for descriptors}

The limit values for the main acoustic class and other classes should be selected taking into account the following circumstances:

- Results of sociological questioning concerning subjective noise perception in accordance to acoustic performance of buildings;

- Acoustical properties of existing buildings;

- Usually used materials and technologies in construction work;

- Experience from other countries, especially countries with the same climatic conditions.

Note that for higher than the basic class requirements the values of standardized spectra adaptation terms may be added to a value of main descriptor looking to account the specific transport noise spectra for façade sound insulation, as well as low frequencies for partitions sound insulation.

\subsection{Procedure for pre-completion testing}

The pre-completion testing is used to facilitate implementation of SCS criteria and belongs to the quality control procedure. The specified acoustic class criteria are applicable for separating walls, floors, façades, entrance doors and common access areas. In general, few alternative options are available for verification of compliance with criteria for the designed sound class: calculations, technical inspections and field measurements. In the case of Lithuania, adopted verification by the field measurements requires only selecting representative structures and spaces to estimate descriptor values and ensure that the critical constructions were included. The tested building achieves the class goal when all measurements comply with all appropriate class limits.

\subsection{Procedures for verification of compliance with an acoustic class}

Verification mainly applies to an entire building. Only when a sufficient number of building elements has been sampled for measurements can the right designation to the one of available classes be ensured. The procedure may involve the following actions:

- The approach when a decision about acoustic class for building may be made from the results of precompletion measurements. Statistical assessment of obtained results may be used as well as various methods for accounting the uncertainty of measurement result;

- Apply the procedure for the additional measures to ensure an obligatory or desired acoustic class perfor- 


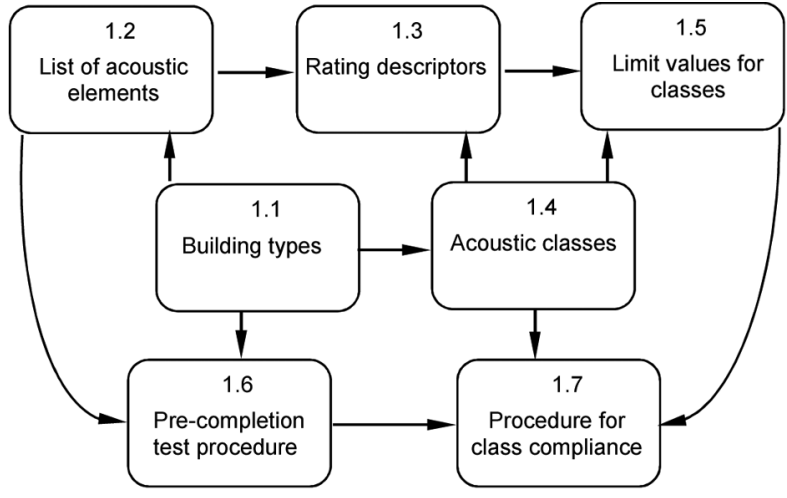

Fig. 1. Block-scheme explaining the development of sound classification scheme for buildings. Numbers in blocks corresponds to the SCS description given in this Section

mance in case the pre-completion testing fails (enhancement of acoustical properties of tested items [elements] by changing design of construction; additional acoustic measurements; others).

Suggested configuration of SCS is explained additionally by the block scheme presented in Figure 1 .

Different descriptors were used for acoustic requirements of buildings in European countries (Rasmussen, Machimbarrena 2014a). Only 10 countries developed SCS for estimation and labelling sound insulation performance, while five countries linked appropriate SCS to national $\mathrm{BC}$, and these are listed in Table 1.

The variety of descriptors used and the different number of acoustic classes, as well as the legal status of SCS concerning linkage to $\mathrm{BC}$, shows the essential difference between some of them. The influence of local circumstances and differences between values of acoustic descriptors in legal requirements for buildings have also been presented in recent papers (Jagniatinskis, Fiks 2004; Rasmussen, Rindel 2010; Garg et al. 2013; Rasmussen, Machimbarrena 2014b; Rasmussen 2014; Berardi, Rasmussen 2015). In the following sections, these positions of the SCS are discussed and investigated.

\section{Descriptors for SCSs}

Today, the $D_{\mathrm{n} T, \mathrm{w}}$ and $R^{\prime}{ }_{\mathrm{w}}$ are the most commonly used descriptors for the assessment of airborne sound insulation between adjacent rooms, and $L^{\prime}{ }_{\mathrm{n} T, \mathrm{w}}$ and $L_{\mathrm{n}, \mathrm{w}}$ are most commonly used for assessing impact sound insulation. First, consider the advantages of using $D_{\mathrm{n} T \text {, w }}$ against $R_{\mathrm{w}}{ }_{\mathrm{w}}$. Formula-related apparent sound reduction index $R^{\prime}$ and standardized sound level difference $D_{\mathrm{n} T}$ for common case may be presented as follows (Jagniatinskis, Fiks 2004):

$$
R^{\prime}-D_{\mathrm{n} T}=10 \lg \frac{k}{0.32 a},
$$

where: $k$ - ratio of the common part of the wall's area belonging to the both adjacent rooms to the whole area of this wall (partition) on the side of the sound receiving room $(k \leq 1$; staggered rooms - when $k<1)$; $a$ - depth (in horizontal sound transmission path) or height (for vertical sound transmission path) of the sound receiving room for rectangular shape of ones. The validity of Eqn (1) was checked in Jagniatinskis and Fiks (2004) by achieved in-situ measurements. The difference $R^{\prime}-D_{\mathrm{n} T}$ depends on the room dimension $a$ and on various coefficient's $k$ values. Graphical expression of Eqn (1) is shown in Figure 2.

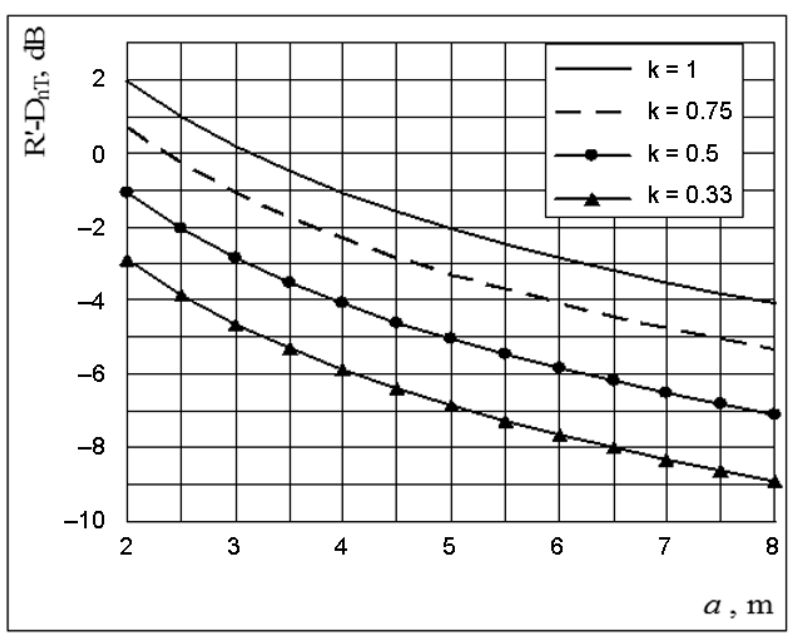

Fig. 2. Dependency of the difference $\left(R^{\prime}-D_{\mathrm{n} T}\right)$ on the room dimension $a$ (modified from Jagniatinskis, Fiks 2004)

For typical non-staggered rooms $(k=1)$ with a receiving room depth (dimension along sound transmission direction) of 3 to $5 \mathrm{~m}$ (for horizontally adjacent rooms) and 2.5 to $3.0 \mathrm{~m}$ (for vertically adjacent rooms - room height), we can see from Figure 2 that the difference $R^{\prime}-D_{\mathrm{n} T}$ for every frequency band is from +0.3 to $-2.0 \mathrm{~dB}$ for horizontally adjacent rooms and from +1.0 to $+0.3 \mathrm{~dB}$ for vertically adjacent rooms. In the horizontal direction of the big room with depth more than $3.0 \mathrm{~m}$, measured airborne sound insulation value expressed through descriptor $D_{\mathrm{n} T}$ on the same separating partition gives higher result when compared with $R^{\prime}$ value. Keeping in mind that legal requirements specify partition's sound insulation performance with the possibility of verifying compliance with an acoustic class, measurements using the $R^{\prime}$ instead of $D_{\mathrm{n} T}$ make the demands for a wall construction more strict. On the contrary, in the vertical direction in dwellings with height about $2.5-2.7 \mathrm{~m}$, measurements using the $R^{\prime}$ descriptor make the demands for a floor construction less strict.

For staggered adjacent rooms as shown in Figure 2, the usage of $D_{\mathrm{n} T}$ allows for exclusion of stricter demands for partition. Moreover, in this case, the usage of $R^{\prime}$ is not suitable due to the low accuracy of determination of common partition area $(S)$ that separates adjacent rooms. Note, that determination of volume $V$, especially for furnished receiving rooms, is also complicated, which leads to low accuracy of this parameter as well. The dependence of absolute deviation $\Delta R^{\prime}$ from the conditional standard deviations of $S\left(\delta_{S}\right)$ and $V\left(\delta_{V}\right)$ parameters 
alone may be presented as $\Delta R^{\prime}=4.34 \sqrt{\left(\delta_{S}^{2}+\delta_{V}^{2}\right)}$, when variations of sound pressure levels and of reverberation time are not taken into account. So, this component of $R$ ' uncertainty may achieve about $0.5 \mathrm{~dB}$. The usage of the $R^{\prime}$ in any case may lead to an additional $1 \mathrm{~dB}$ uncertainty in its determination for the aforementioned in situ measurement situations. In these cases, the usage of $D_{\mathrm{n} T}$ descriptor is preferable because it does not depend on the geometrical dimensions of the receiving room.

However, on the other hand, despite the relatively greater uncertainty $R$ ' must also be determined, because it directly describes the insulation properties of the investigated partition for airborne sound and may be compared with the analogous laboratory $R$ values. Furthermore, the in situ situations described hereafter using the $D_{\mathrm{n} T}$ descriptor for horizontal measurements are controversial. This situation may arise for relative large (volume more than $60 \mathrm{~m}^{3}$ ) receiving rooms, for example, when room dimension $a$ (depth in horizontal sound transmission path) is more than $6 \mathrm{~m}$. In practice, it may happen that such large rooms, after the measurements are accomplished, may be divided later, e.g. into two different rooms (spaces). Hence, the volume of the receiving room $V_{1}$ reduces to $V_{2}$. Obviously, $R$ ' value has not changed. For rectangular receiving rooms, the difference between $D_{\mathrm{n} T, 1}$ (result for initial room) and $D_{\mathrm{n} T, 2}$ (result corresponds to the reduced room) may be expressed by the equation:

$$
D_{\mathrm{n} T, 1}-D_{\mathrm{n} T, 2}=10 \lg \frac{1}{k_{V}}
$$

where: $k_{V}$ - coefficient is equal to proportion $V_{2} / V_{1}$.

The validity of Eqn (2) was checked by in-situ measurements at different stages of development of a new building (Jagniatinskis, Fiks 2009). Graphical expression for this case is shown in Figure 3.

From Figure 3, it can be seen that the reduction of the receiving room's volume by $20 \%$ leads to $D_{\mathrm{n} T}$ decrement by $1 \mathrm{~dB}$, and when the receiving room is divided into two equal parts, $D_{\mathrm{n} T}$ decreases by $3 \mathrm{~dB}$. So from

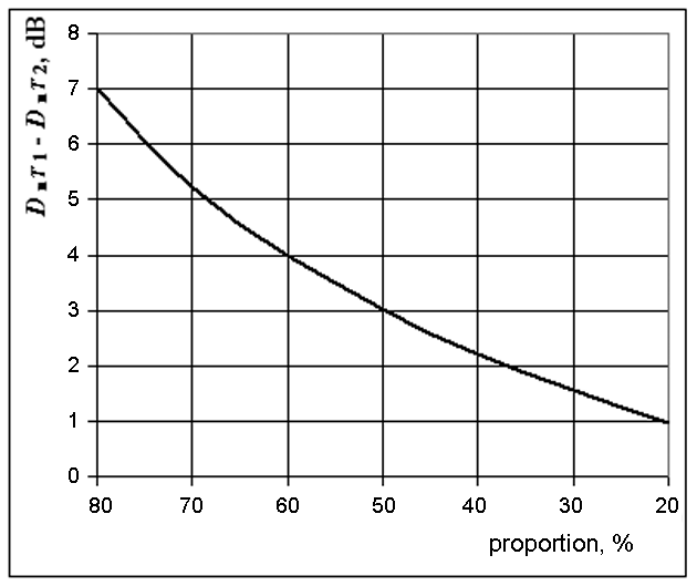

Fig. 3. Changes in $D_{\mathrm{n} T}$ values in case when the receiving room's volume is reduced on the some proportion of initial volume the above-presented results, it may be concluded that the best decision for airborne sound insulation performance of walls that separate two adjacent rooms is to take into account either the $R^{\prime}{ }_{\mathrm{w}}$ or the $D_{\mathrm{n} T, \mathrm{w}}$ descriptor as a performance criteria for SCS.

Analogously consider the advantages of using any of $L_{\mathrm{n} T, \mathrm{w}}^{\prime}$ or $L_{\mathrm{n}, \mathrm{w}}^{\prime}$ descriptors as an SCS criterion for impact sound insulation properties of floors, which vertically separates two adjacent rooms. The formula that relates normalized $L_{\mathrm{n}}^{\prime}$ and standardized $L_{\mathrm{n} T}^{\prime}$ impact sound pressure levels is presented below (Jagniatinskis, Fiks 2004):

$$
L_{\mathrm{n}}^{\prime}-L_{\mathrm{n} T}^{\prime}=10 \lg (0.032 V),
$$

where: $V$ - volume of sound receiving room.

Dependencies of Eqn (3) graphically expressed in Figure 4.

For typical dwellings, where a room volume is about $30 \mathrm{~m}^{3}$ to about $50 \mathrm{~m}^{3}$, we find, from Figure 4, that considerable differences for every frequency band are from 0 to $2 \mathrm{~dB}$. So, practically, the usage of $L^{\prime}{ }_{\mathrm{n}}$ descriptor for impact sound insulation measurements makes demands for appropriate acoustic classes stricter when compared with $L_{\mathrm{n} T}^{\prime}$ descriptor; thus, $L_{\mathrm{n}}^{\prime}$ application is undesirable for very large rooms.

As $L_{\mathrm{n}}^{\prime}$ descriptor depends on the volume of receiving room, the accuracy of determination of this parameter $\delta_{V}$ especially for furnished rooms also influences $L_{\mathrm{n}}{ }_{\mathrm{n}}$ values according to the expression for their absolute deviation when the variations of sound pressure levels and of reverberation time are not taken into account:

$$
\Delta L_{\mathrm{n}}^{\prime}=4.34 \delta_{V},
$$

where: $\delta_{V}$ - conditional standard deviation of room's volume $V$ determination.

This additional uncertainty of $L_{\mathrm{n}}^{\prime}$ could also be important for the aforementioned in situ measurement situations and may lead to an additional $1 \mathrm{~dB}$ uncertainty in determining descriptor $L_{\mathrm{n}}{ }_{\mathrm{n}}$. In these cases, usage of $L_{\mathrm{n} T}^{\prime}$ descriptor is preferable because it does not depend on geometrical dimensions of the receiving room. On the

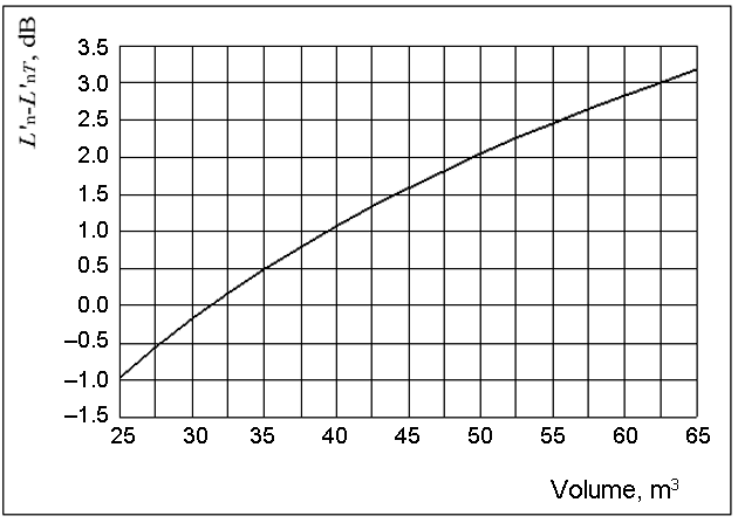

Fig. 4. Dependency of the difference $L_{\mathrm{n}}-L_{\mathrm{n} T}$ from receiving room's volume (modified from Jagniatinskis, Fiks 2004) 
other hand, $L_{\mathrm{n}, \mathrm{w}}$ must also be determined when possible, because it directly describes insulation performance of the investigated partition (floor) for impact sound and could be used for comparison with the analogous laboratory $L_{\mathrm{n}, \mathrm{w}}$ value.

Optimizing façade sound insulation in SCS must be concerned with the noise levels dominated in the outdoor environment. First, the environment conditions must be classified according to noise levels. As descriptor for such classification could be chosen, the annual composite day-evening-night level $L_{\text {den }}$ was introduced in the EU as a mandate according to Environmental Noise Directive (EU Directive 2002/49/EC 2002) for noise mapping and environmental noise pollution evaluation. Other descriptors that characterize the building's outdoor environment noise (e.g. $L_{\text {night }}, L_{\max }$ or its combination) could be also adopted. It is clear that the descriptor chosen for environment noise classification must be directly related to the appropriate descriptor for airborne sound insulation of façades presented in the relevant EN/ISO standard (ISO 16283-3:2016). For example, the pair of $L_{\mathrm{den}}$ and standardized level difference $L_{\mathrm{ls}, 2 \mathrm{~m}, \mathrm{n} T}$ may be considered as one of the possible realisations for façade classification. Because of peculiarities that arose in façade in situ measurements, detailed observation of available descriptor usage requires special consideration, and so is not included in this paper.

As can be seen from Table 2, in European countries, various spectra adaptation terms are used to evaluate pink and typical transport noise spectra concerning airborne sound insulation and noise level peaks at single (low) frequencies concerning impact sound insulation. Note that spectra adaptation terms in various SCS are mainly used for higher acoustic quality classes (Jagniatinskis et al. 2013; Rasmussen, Rindel 2010; Garg et al. 2013) for evaluation especially at low-frequency bands, e.g. from $50 \mathrm{~Hz}$. How it could be realized depends on various factors (e.g., tradicionally used constructions and materials in buildings, step in $\mathrm{dB}$ between acoustic classes, etc.) and will be considered in the next section.

\section{Rating values for sound insulation classes}

The acoustic comfort levels established in SCS primarily depend on the specific demands labelled for the main class linked to the new buildings and are expressed as a limit value of appropriate SCS descriptor. The limit value is established considering the following circumstances:

- Sound insulation performance values in existing buildings must be collected;

- Applicability of traditionally used materials and constructions must be investigated;

- Trends in construction development taking into account the raised demands for acoustic comfort must be known;

- Other experiences in building performance regulation, especially in countries with the same climatic conditions must be adopted;

- The results of sociological questioning concerning relations between the subjective noise perception and the acoustic quality must be available.

These factors help to determine the practical ranges for sound insulation values in decibels for building partitions between adjacent rooms as well as outdoors (walls, floors and facade). The particular rating set of values (upper or lower permissible values) may be optimally chosen to describe different acoustic quality (class) for considered acoustic quantity. The cost of implementation must be taken into account when it is mandatory to achieve normal or enhanced acoustic comfort in new buildings.

The sociological estimations assumed that in acceptable comfort conditions the percentage of the passive complaints (initiated by occupants of dwellings) concerning annoying environment must be less than $10 \%$ of all inhabitants. The acceptable value of annoyed inhabitants rises to about $30 \%$ of all respondents when complaint is initiated via the questionnaire (or pushed by questioning). These inferences are well known (Bradley 1982; Bodlund 1984; Weber et al. 1986) and were applied to indicate acoustical perception of inhabitants.

The requirements have two main quality levels related to the cost and acoustic comfort. The so-called "normal acoustic comfort" level is a compromise between the cost of construction and acoustic comfort. In this category, the acoustic requirement level does not increase the building cost and is such that at least about $70 \%$ of the questioning inhabitants are satisfied with the sound insulation. Our experience as well as Danish (DS 490:2007) and The Netherlands (NEN 1070:1999) standards showed that "improved acoustic comfort class" may be achieved when more than $90 \%$ of the inhabitants are satisfied with

Table 2. Rating values of subjective questioning in case of 5 sound classes for dwellings (adopted to Lithuania case)

\begin{tabular}{l|c|c|c}
\hline \multicolumn{1}{c|}{ Sound class descriptions } & \multicolumn{2}{c}{ Occupants' evaluation, \% } \\
\cline { 2 - 4 } & Good or very good & No opinion & Poor \\
\hline A. Sound class with excellent comfort & $>90$ & $<10$ & - \\
B. Sound class with enhanced comfort & 70 to 85 & 5 to 20 & $<10$ \\
$\begin{array}{l}\text { C. Sound class with normal comfort } \\
\text { D. Sound class with limited comfort in renovated buildings }\end{array}$ & 50 to 65 & 5 to 20 & $<30$ \\
$\begin{array}{l}\text { E. Sound class with limited comfort (correspond de facto conditions in old } \\
\text { dwellings) }\end{array}$ & 30 to 45 & 5 to 45 & 25 to 50 \\
\hline
\end{tabular}


the sound insulation. Additionally, it also means an increase in the building cost. The survey data indicate the likelihood that 50 to $65 \%$ of the people should have a good or very good assessment of airborne and impact sound insulation in a new residential building with minimal sound class (Rasmussen, Rindel 2003; DS 490:2007). It is also unlikely that more than $30 \%$ of the people will evaluate the acoustic quality negatively. A very similar evaluation expected in the Nordic draft (INSTA 122:1998) described acoustic requirements to the minimum allowable acoustic comfort class. Only slight differences could be seen on probably negative assessment provided by the population, which would not exceed $20 \%$. In the Netherlands (NEN 1070:1999), it would vary from 10 to $25 \%$. On the basis of this, it can be suggested that when SCS is composed of five acoustic classes (A, B, C, D and E), the subjective evaluation of each sound class (indoor acoustic comfort) could be summarized as listed in Table 2 .

Usually it is important to achieve normal acoustic comfort (Class C, for example, as in Table 2) conditions in newly constructed buildings. The experience described below was gained from the preparation of the Lithuanian SCS when looking to set the limit values for sound insulation performance rating. About 2000 airborne and impact sound insulation measurements of partitions in dwellings were accomplished since 2004 when the acoustic pre-completion testing for new buildings became mandatory, like in the United Kingdom (Craik et al. 1999). Some acoustical data were partly (when measurements are performed in inhabited premises) complemented by the inhabitants' opinion about acoustic comfort level in their premises (directly). These semi-sociological data were compared to the sociological questioning data of several countries with same climatic condition as Lithuania (Canada, Nordic countries, Russia) and were used for the preparation of the Lithuanian SCS (Bradley 1982; Weber et al. 1986; Krejtan 1990; Jagniatinskis 2003). The statistical results of processing common data are shown in Figures 5-7. The figures show the percentage of the

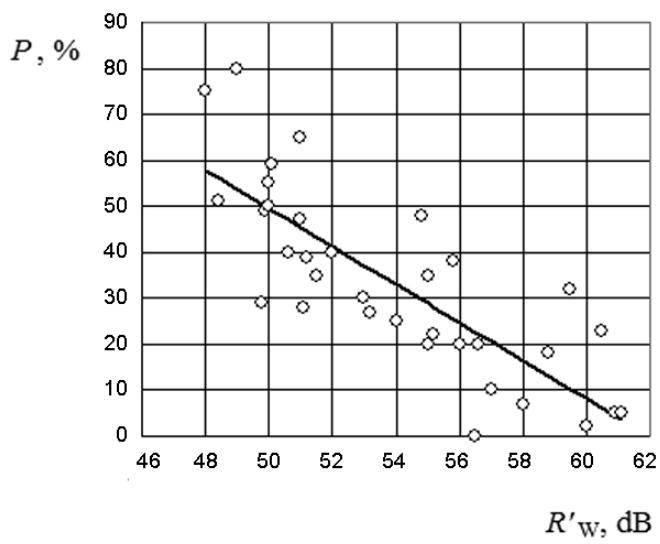

Fig. 5. Percentage of the occupants which evaluated their acoustic comfort level as poor depending on the vertical partition's (wall) weighted apparent sound reduction index $R^{\prime}{ }_{\mathrm{w}}$ value (modified from Jagniatinskis 2003)

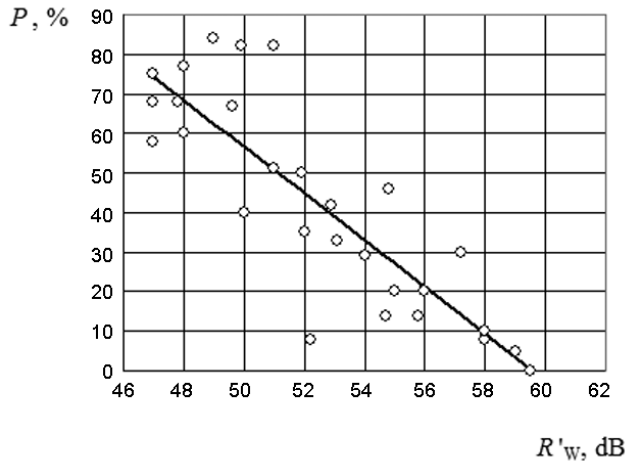

Fig. 6. Percentage of the occupants which evaluated their acoustic comfort level as poor depending on the horizontal partition's (floor) weighted apparent sound reduction index $R^{\prime}{ }_{\mathrm{w}}$ value (modified from Jagniatinskis 2003)

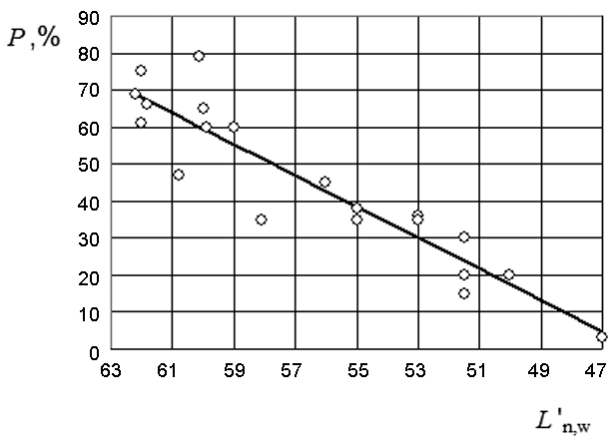

Fig. 7. Percentage of the occupants which evaluated their acoustic comfort level as poor depending on the floor's weighted normalized impact sound pressure level $L_{\mathrm{n}, \mathrm{w}}$ value (modified from Jagniatinskis 2003)

occupants who evaluated their acoustic comfort level as poor depending on the acoustical performance of partitions, together with appropriate regression lines.

The appropriate results of regression analysis are presented in Table 3.

Table 3. Results of regression analysis using data from Figures 5-7 adopted for Lithuanian case

\begin{tabular}{c|c|c}
\hline \multicolumn{1}{c|}{ Descriptor } & Regression line & $\begin{array}{c}\text { Correlation } \\
\text { coefficient }\end{array}$ \\
\hline$R^{\prime}{ }_{\mathrm{w}}$ for walls & $\begin{array}{l}P(\%)=236.94-3.77 R^{\prime}{ }_{\mathrm{w}} \\
\left(R_{\mathrm{W}}^{\prime}=62.78-0.26 P(\%)\right)\end{array}$ & 0.80 \\
\hline$R^{\prime}{ }_{\mathrm{w}}$ for floors & $\begin{array}{l}P(\%)=342.86-5.72 \\
\left(R_{\mathrm{w}}^{\prime}=59.91-0.17 P(\%)\right)\end{array}$ & 0.83 \\
\hline$L_{\mathrm{n}, \mathrm{w}}$ & $\begin{array}{l}P(\%)=4.21 L^{\prime}{ }_{\mathrm{n}, \mathrm{w}}-193.28 \\
\left(L_{\mathrm{n}, \mathrm{w}}^{\prime}=45.86+0.23 P(\%)\right)\end{array}$ & 0.93 \\
\hline
\end{tabular}

The summarized results presented in Figures 5-7 and Tables 2, 3 allows estimate limit values intervals for rated classes and is presented in Table 4.

The limit values for the Lithuanian SCS case were set by taking into account the percentage of estimation considered as a "poor" (as listed in Table 2) as well as from the regression lines obtained by our investigation (presented in Figs 5-7). For example, the requirements 
Table 4. The limit values intervals estimated for sound insulation performance of each sound class

\begin{tabular}{c|c|c|c}
\hline \multirow{2}{*}{$\begin{array}{c}\text { Acoustic } \\
\text { class }\end{array}$} & \multicolumn{2}{|c|}{$\begin{array}{c}\text { Airborne sound } \\
\text { insulation, } R^{{ }_{\mathrm{w}}}, \mathrm{dB}\end{array}$} & $\begin{array}{c}\text { Impact sound } \\
\text { insulation, } L_{\mathrm{n}, \mathrm{w}}, \mathrm{dB}\end{array}$ \\
\cline { 2 - 4 } & walls & floors & floors \\
\hline $\mathrm{A}$ & $>62$ & $>60$ & $<47$ \\
$\mathrm{~B}$ & $60-61$ & $58-59$ & $48-47$ \\
$\mathrm{C}$ & $55-57$ & $54-56$ & $53-51$ \\
$\mathrm{D}$ & $49-52$ & $51-53$ & $58-55$ \\
\hline
\end{tabular}

established in developed SCS are listed in Table 5 for airborne sound insulation and in Table 6 for impact sound insulation (STR 2.01.07:2003). On the basis of the abovepresented percentage of complaints and rating percentage for different sound classes as suggested in Table 2 as well as taking into account the obtained regression lines shown in Figures 5-7, limit values for Lithuanian SCS were accepted.

Table 5. The requirements of airborne sound insulation established for vertical (walls) and horizontal (floors) partitions between adjacent premises in dwellings, as the lowest limit values of each sound class (STR 2.01.07:2003)

\begin{tabular}{|c|c|c|c|c|c|}
\hline \multirow{3}{*}{ Type of protected space } & \multicolumn{5}{|c|}{ Sound class denotation } \\
\hline & $\mathrm{A}$ & $\mathrm{B}$ & $\mathrm{C}$ & $\mathrm{D}$ & $\mathrm{E}$ \\
\hline & \multicolumn{5}{|c|}{ 1) Limit values (dB) } \\
\hline $\begin{array}{l}\text { Habitable room from public } \\
\text { premises (work or service) as } \\
\text { well as common garage in the } \\
\text { building }\end{array}$ & 68 & 63 & 60 & 55 & 52 \\
\hline $\begin{array}{l}\text { Habitable room from room of } \\
\text { other habitable premises or from } \\
\text { common adjacent spaces of the } \\
\text { building }\end{array}$ & 63 & 58 & 55 & 52 & 48 \\
\hline $\begin{array}{l}\text { At least one bedroom from other } \\
\text { room in the same habitable } \\
\text { premises }\end{array}$ & 48 & 44 & $41^{2)}$ & - & - \\
\hline \multicolumn{6}{|c|}{$\begin{array}{l}\text { Notes: }{ }^{1)} \text { Descriptors } R^{\prime}{ }_{\mathrm{W}} \text { or } D_{\mathrm{nTw}} \text { applied to C, D and E class- } \\
\text { es. The limit values for A and B classes include spectrum ad- } \\
\text { aptation term } C_{50-3150 .} \text { It is recommended use this term for } \\
\text { class } \mathrm{C} \text { also, then the limit value reduced by } 2 \mathrm{~dB} \text { (so called } \\
\text { " } 2 \mathrm{~dB} \text { rule"); } \\
\text { 2) Recommended to apply when dwelling comprise more than } \\
\text { two bedrooms. }\end{array}$} \\
\hline
\end{tabular}

In the Lithuanian case, by taking into account the reasons mentioned in Section 3, a partition's airborne sound insulation performance was described simultaneously using $R_{\mathrm{w}}^{\prime}$ and $D_{\mathrm{n} T \mathrm{w}}$ descriptors with the same limit value for both. The limit value for class $\mathrm{C}$ set at $55 \mathrm{~dB}$ is intended to describe the acoustic comfort in terms of airborne sound insulation performance in the newly erected buildings. The step change between sound classes varies from 3 to $5 \mathrm{~dB}$. The spectrum adaptation term $C_{50-3150}$ is introduced as mandatory for acoustic classes (B and A), with enhanced acoustic comfort to account for and
Table 6. The requirements of impact sound insulation established for horizontal partitions (floors) between adjacent premises in dwellings, as the maximal limit values of each sound class (STR 2.01.07:2003)

\begin{tabular}{l|c|c|c|c|c|c}
\hline \multirow{2}{*}{\multicolumn{1}{c}{ Type of protected space }} & \multicolumn{5}{|c}{ Sound class denotation } \\
\cline { 2 - 6 } & A & B & C & D & E \\
\cline { 2 - 6 } & \multicolumn{5}{|c}{ Limit values (dB) } \\
\hline $\begin{array}{l}\text { Habitable room from above } \\
\text { placed public premises (work or } \\
\text { service) }\end{array}$ & 38 & 43 & 48 & 53 & 58 \\
\hline $\begin{array}{l}\text { Habitable room from above } \\
\text { placed room of other habitable } \\
\text { premises }\end{array}$ & 43 & 48 & $\mathbf{5 3}$ & 58 & 60 \\
\hline $\begin{array}{l}\text { Habitable room from above } \\
\text { placed common spaces adjacent } \\
\text { to this room }\end{array}$ & 48 & 53 & 58 & 60 & 63 \\
\hline $\begin{array}{l}\text { At least one bedroom from } \\
\text { above placed other room in the } \\
\text { same premises }\end{array}$ & 53 & 58 & $60^{2)}$ & - & - \\
\hline
\end{tabular}

Notes: ${ }^{1)}$ Descriptor $L_{\text {nw }}^{\prime}$ applied to C, D and E classes. The limit values for $\mathrm{A}$ and $\mathrm{B}$ classes include spectrum adaptation term $C_{50-3150}$ and descriptor $L_{n, w}^{\prime}+C_{\mathrm{I}, 50-2500}$ is applied._It is recommended that this term to be used for class $\mathrm{C}$ also, and then limit values remain the same (so called " $0 \mathrm{~dB}$ rule");

2) Recommended to apply when dwelling comprise more than two bedrooms.

strengthen the requirements for the low-frequency bands. So for these classes, $R_{\mathrm{W}}^{\prime}+C_{50-3150}$ or $D_{\mathrm{n} T \mathrm{~W}}+C_{50-3150}$ descriptors are applicable. The so-called " $2 \mathrm{~dB}$ rule" (see Table 5) was introduced by taking into account the sound insulation properties traditionally applicable in country with the masonry wall partitions that typically have high $C_{50-3150}$ value from -2 to $0 \mathrm{~dB}$. So these types of partitions will be preferable to use for A and B classes. This is also directed against the usage of the "enhanced" partitions constructed from main masonry wall and additional plasterboard layer with cavity between the wall and this layer. The pre-completion tests results confirm this proposition because the $C_{50-3150}$ value for such partitions is obtained in the range from -7 to $-4 \mathrm{~dB}$ (Mickaitis et al. 2011). In addition, strengthened sound insulation requirements are applied for habitable rooms neighboured with public premises to keep necessary comfort conditions due to the higher protection against noise from non-residential premises.

The lack of in situ measurement results for impact sound insulation determines that only one rating quantity $L_{n, w}^{\prime}$ was chosen for sound classification. Nowadays, the results, presented in Section 3 to characterize floors' impact sound insulation performance, strongly recommend the use of $L_{\mathrm{n}, \mathrm{w}}^{\prime}$ and $L_{\mathrm{n} T, \mathrm{w}}^{\prime}$ descriptors with the same limit value for both. The limit value for class $\mathrm{C}$ is set at $53 \mathrm{~dB}$ to describe the acoustic comfort in terms of impact sound insulation performance in the newly erected buildings. The increase in steps between classes varies from 2 to $5 \mathrm{~dB}$. The spectrum adaptation term $C_{\mathrm{I}, 50-2500}$ is used 
as mandatory for acoustic classes with enhanced acoustic comfort (B and $\mathrm{A}$ ) to account for and strengthen the requirements at the low-frequency bands. The " $0 \mathrm{~dB}$ " rule was introduced to take into account the insulation properties of the properly mounted heavyweight floating floors that have low $C_{\mathrm{I}, 50-2500}$ value mainly from $-2 \mathrm{~dB}$ to $+1 \mathrm{~dB}$. So, these types of floors will be preferably used for A and B classes. In this way, the influence of low frequency is assessed more accurately for the impact sound sources, and this is important for subjective estimation of fulfilled requirements.

The questioning data collected during pre-completion testing of the newly erected buildings endorse results obtained during the investigation in years 2004-2014 and are listed in Table 4. The legal requirements listed in Tables 5 and 6 show how the limit values are set in building technical regulation (STR 2.01.07:2003). Numerous measurements performed during pre-completion testing in general demonstrate successful practical implementation of awaited acoustical comfort conditions expressed through sound insulation requirements rated for different sound class in dwellings.

\section{Conclusions}

In the Lithuanian case, the SCS was designated to establish legal requirements for protection against noise in buildings. Enforcement of appropriate technical building regulation (STR 2.01.07:2003) by mandatory pre-completion acoustical testing of new and renovated buildings ensures better acoustical comfort in habitable premises. SCS demonstrates advantages of the sustainable building approach by labelling sound insulation performance too. Comparison analysis against a similar approach to manage sound insulation requirement in other countries allows for a description of findings during SCS development. The knowledge about the relationship of the subjective indicators of achieved indoor acoustical comfort with the objective value of appropriate sound insulation performance between premises allows for setting SCS in general. Limit values for sound insulation rating descriptors in each sound class and amount of sound classes in the scheme are selected from the trends in new and old buildings performance as well as needs of real-estate developers so as to enhance protection against noise.

The experience and information collected in Lithuania during 10 years of practical application of the SCS as the buildings technical regulation shows the possibility of labelling acoustical comfort in dwellings corresponding to different levels of sound insulation. Similar schemes developed in several European countries have a significant diversity in terms of descriptors, number of classes and class intervals. The habitable premises may only be considered as a first step to develop harmonized SCS. Recently proposed "acoustic classification scheme for dwellings" developed by the European COST Action TU0901 raised discussions and introduced new metrics to raise the attention to more stringent sound insulation requirements.

Analysing advantages of various sound insulation descriptors applicable in SCS, it has been shown that the usage of both $R^{\prime}$ and $D_{\mathrm{n} T}$ descriptors simultaneously on the equal limit value is more appropriate to estimate partitions' airborne sound insulation performance. A similar solution was recommended for floors' impact sound insulation performance by additionally applying the other pair of $L_{\mathrm{n}}^{\prime}$ and $L_{\mathrm{n} T}^{\prime}$ ones. This allows to exclude disadvantages of $R^{\prime}$ and $L^{\prime}{ }_{\mathrm{n}}$ descriptors, which become impracticable to use for the measurements of staggered rooms as well as for very large and furnished receiving rooms, where geometrical dimensions influence measurement accuracy. The proposed approach allows for taking into account the particular field situation to choose a more suitable descriptor for evaluation sound insulation performance. The different values obtained on the same construction justify that the $D_{\mathrm{n} T}$ and $L_{\mathrm{n} T}$ descriptors are more related to the subjective perception the noise in premises, while the other $R$ ' and $L^{\prime}{ }_{\mathrm{n}}$ ones were related to the objective wall's and floor's sound insulation properties. For this reason, the rating by the any descriptor selected from $R^{\prime}{ }_{\mathrm{w}}$ or $D_{\mathrm{n} T, \mathrm{w}}$ as well as the $L_{\mathrm{n}, \mathrm{w}}^{\prime}$ or $L_{\mathrm{n} T, \mathrm{w}}^{\prime}$ was included into the SCS verification procedure.

The decision about the limit values adopted for inclusion in the each sound class of SCS comes from justification of variable steps between classes. Factors such as geographical climate conditions, construction work traditions, neighbour countries experience and, if available, subjective estimations from sociological investigations are also taken into consideration. The appropriate procedure is demonstrated in the Lithuanian case where Germany and Nordic countries' experience was used for the interpretation of sociological questioning and complaints data. The limit values for each sound class are found from the built appropriate regression lines of the questioning data. For class $\mathrm{C}$ (mandatory requirement for new buildings in Lithuania), the limit value (lowest permitted) linked to $\mathrm{BC}$ was set at $55 \mathrm{~dB}$ for airborne sound insulation between dwellings. In addition, the limit value (highest permitted) was set at $53 \mathrm{~dB}$ for impact sound insulation between dwellings. These values practically ensure that no more than $30 \%$ of the inhabitants during active questioning can evaluate their indoor acoustical comfort as a poor. The limit values accepted for sound class $\mathrm{E}$ were obtained during investigations in the existing buildings and were linked to $\mathrm{BC}$ as a requirement for renovated buildings, looking at reducing the risk of overcost to improve sound insulation performance.

\section{Disclosure statement}

Authors declare that they do not have any competing financial, professional, or personal interests from other parties. 


\section{References}

Berardi, U.; Rasmussen, B. 2015. A comparison between national scheme for the acoustic classification of dwellings in Europe and in the U.S., International Journal of Acoustics and Vibration 20(2): 63-68. https://doi.org/10.20855/ijav.2015.20.2369

Bodlund, K. 1984. Ljjudklimatet i moderna svenska bostäder. Stockholm: Byggforsknings-rädet. Rapport R96:1984 (in Swedish).

Bradley, J. S. 1982. Subjective rating of the sound insulation of party walls (a pilot study). Ottawa: National Research Council Canada. Building Researche Note no. 196.

COST Action TU 0901. Integrating and Harmonizing sound insulation aspects in sustainable urban housing constructions [online], [cited 12 September 2016]. Available from Internet: http://www.cost.esf.org

Craik, R. J. M.; McPherson, A.; Somerville, A. W. M. 1999. The relationship between post-construction testing and sound insulation performance, Applied Acoustics 57: 79-87. https://doi.org/10.1016/S0003-682X(98)00044-9

DS 490:2007. Lydklassifikation af boliger (Sound classification of dwellings). Danish standard.

EU Directive 2002/49/EC relating to the Assessment and Management of Environmental Noise, Official Journal of the European Communities, 2002, No. L 189.

Garg, N.; Kumar, A.; Maji, S. 2013. Practical concerns associated with use of single number rating in measuring sound transmission loss properties of partition panels, Archives of Acoustics 38: 115-26. https://doi.org/10.2478/aoa-2013-0014

Gerretsen, E. 2009. Model-based assessment scheme for acoustic quality classes in buildings, in Proceedings of NAG/DAGA 2009, Rotterdam, Netherlands.

Guigou-Carter, C.; Wetta, R.; Foret, R.; Chene, J.-B. 2012. Elements for an acoustic classification of dwellings and apartment buildings in France, in Proceedings of the Acoustics 2012 Nantes Conference, 23-27 April 2012, Nantes, France, 3081-3086.

INSTA 122:1998. Sound classification of dwellings. Nordic country standard.

ISO 16283-1:2014. Acoustics - Field measurement of sound insulation in buildings and of building elements - Part 1: Airborne sound insulation. Geneva: International Organization for Standardization.

ISO 16283-2:2015. Acoustics - Field measurement of sound insulation in buildings and of building elements - Part 2: Impact sound insulation. Geneva: International Organization for Standardization.

ISO 16283-3:2016. Acoustics - Field measurement of sound insulation in buildings and of building elements - Part 3: Façade sound insulation. Geneva: International Organization for Standardization.

IST 45:2011. Acoustic condition in buildings - sound classification of various types of buildings. Icelandic Standard.

Jagniatinskis, A. 2003. Relationship between draft Lithuanian regulation "Protection against noise" and Nordic standards, Ultragarsas 2(47): 106-108.

Jagniatinskis, A.; Fiks, B. 2004. Application of different descriptors for in situ sound insulation, in InterNoise 2004, Prague, Czech Republic. Paper ID 609.

Jagniatinskis, A.; Fiks, B. 2009. Misunderstandings about airborne sound insulation quality estimated in-situ with different descriptors, in EURONOISE 2009: $8^{\text {th }}$ European Conference on Noise Control, 26-28 October 2009, Edinburgh, Scotland. Stuttgart: S. Hirzel Verlag, 95(1): 104.

Jagniatinskis, A.; Mickaitis, M.; Fiks, B. 2013. Development classification scheme for evaluation dwellings sound insulation performance in Lithuania, Procedia Engineering 57: 443-449.

Krejtan, V.G. 1990. Zashchyta ot vnutrennych shumov $v$ zhilych domach [Protection against noise in dwellings]. Moscow: Strojizdat (in Russian).

La méthode qualitel:2008. Association Qualitel. French Standard [online], [cited 12 September 2016]. Available from Internet: http://www.cerqual.fr

Ljunggren, F.; Simmons, C.; Hagberg, K. 2014. Correlation between sound insulation and occupants' perception - Proposal of alternative single number rating of impact sound, Applied Acoustics 85: 57-68.

https://doi.org/10.1016/j.apacoust.2014.04.003

Mickaitis, M.; Jagniatinskis, A.; Fiks, B. 2011. Mūriniu konstrukciju garso izoliavimas papildomais lanksčiais sluoksniais, Statybinés konstrukcijos ir technologijos 3(1): 33-40 (in Lithuanian).

NEN 1070:1999. Geluidwering in gebouwen - Specificatie en beoordeling van de kwaliteit" (Noise control in buildings - specification and rating of quality). Netherlands standard.

NS 8175:2012. Lydforhold i bygninger, Lydklassifisering avulike bygningstyper" (Sound conditions in buildings - sound classes for various types of buildings). Norway standard.

Nurzynski, J. 2007. Evaluation of acoustic performance of multifamily buildings, open building manufacturing approach, in Inter-Noise 2007, 28-31 August 2007, Istanbul, Turkey. Paper ID 101.

ÖNORM B 8115-5:2012: Schallschutz und Raumakustik im Hochbau - Teil 5: Klassifizierung. Austrian standard.

Rasmussen, B. 2004. Sound insulation between dwellings Classification schemes and building regulations in Europe, in Proceedings of Inter-Noise 2004, Prague, Czech Republic. 8 p.

Rasmussen, B. 2010. Sound insulation between dwellings Requirements in building regulations in Europe, Applied Acoustics 71(4): 373-385. http://dx.doi.org./10.1016/j.apacoust.2009.08.011

Rasmussen, B. 2011. Sound classification of dwellings - A diversity of national schemes in Europe, in Proceedings of Forum Acusticum 2011, European Acoustics Association EAA, 1799-1804.

Rasmussen, B. 2014. International proposal for an acoustic classification scheme for dwellings - Background and perspectives, in Inter-Noise 2014, 16-19 November, Melbourn, Australia. Paper 971.

Rasmussen, B.; Machimbarrena, M. (Eds.) 2014a. COST Action TU0901 - Building acoustics throughout Europe. Volume 1: Towards a common framework in building acoustics throughout Europe. DiScript Preimpresion, S. L. [online], [cited 12 September 2016]. Available from Internet: http://www.costtu0901.eu/tu0901-e-books.html

Rasmussen, B.; Machimbarrena, M. 2014b. Existing Sound Insulation Performance Requirements and Classification Schemes For Housing Across Europe, in COST Action TU0901 - Building acoustics throughout Europe. Volume 1: Towards a common framework in building acoustics throughout Europe. DiScript Preimpresion, S. L., Ch. 2: $31-54$.

Rasmussen, B.; Rindel, J. H. 2003. Sound insulation of dwellings - legal requirements in Europe and subjective evaluation of acoustical comfort, in $D A G A^{\prime} 03$, Aachen, Germany. Paper ID 1723.

Rasmussen, B.; Rindel, J. H. 2010. Sound insulation between dwellings - Descriptors applied in building regulations in Europe, Applied Acoustics 71: 171-180. https://doi.org/10.1016/j.apacoust.2009.05.002 
Regulation No 305/2011 of the European Parliament and of the Council of 9 March 2011 laying down harmonised conditions for the marketing of construction products and repealing Council Directive 89/106/EEC, Official Journal of the European Union 4.4.2011.

Scholl, W.; Lang, J.; Wittstock, V. 2011. Rating of sound insulation at present and in future. The revision of ISO 717, Acta Acustica united with Acustica 97(4): 686-698. https://doi.org/10.3813/AAA.918448

SFS 5907:2004. Rakennusten Akustinen Luokitus [Acoustic classification of spaces in buildings]. Finnish standard.

SS 25267:2004. Byggakustik - Ljudklassning av utrymmen $i$ byggnader - Bostäder (Acoustics - Sound classification of spaces in buildings - Dwellings). Swedish standard.
STR 2.01.07:2003 Pastatu vidaus ir išorès aplinkos apsauga nuo triukšmo [Lithuanian building regulations. Protection against noise in buildings]. Lithuania: Lietuvos Respublikos Seimas (in Lithuanian).

UNI 11367:2010. Acustica in edilizia - Classificazione acustica delle unita immobiliari - Procedura di valutazione e verifica in opera [Building acoustics - Acoustic classification of building units - Evaluation procedure and in-situ measurements]. Italian standard.

VDI 4100:2012. Schallschutz von Wohnungen - Kriterium für Planung und Beurteilung [Noise control in dwellings criteria for planning and assessment]. German standard.

Weber, R.; Merkel, H.; Rossbach-Lochmann, H.; Buchta, E.; Gösele, K. 1986. Schallschutz in Mehrfamilienhäusern aus dem Sicht der Bewhner. Stuttgart: IRB Verlag, F 2049.

Aleksandras JAGNIATINSKIS. Dr, Senior research assistant and the Head of the Acoustic laboratory of Scientific Institute of Thermal Insulation, Vilnius Gediminas Technical University (VGTU). Research interests: building acoustics, acoustical properties of building materials, acoustical measurements.

Boris FIKS. Dr, Research assistant at the Acoustic laboratory of Scientific Institute of Thermal Insulation, Vilnius Gediminas Technical University (VGTU). Research interests: building acoustics, acoustical properties of building materials, acoustical measurements.

Marius MICKAITIS. Dr, Assoc. Prof, the Head of the Department of Architectural Engineering, Vilnius Gediminas Technical University (VGTU). Research interests: acoustics, architectural engineering.

Ritoldas ŠUKYS. Dr, Professor and the Head of the Department of Labor Safety and Fire Protection, Vilnius Gediminas Technical University (VGTU). Research interests: human safety, safety engineering. 